\title{
An Instructional Module on Thermally Coupled Columns for Undergraduate Chemical Engineering Separations
}

\section{Dr. Priscilla J Hill, Mississippi State University}

Dr. Priscilla Hill is currently an associate professor in the Dave C. Swalm School of Chemical Engineering at Mississippi State University. She has research interests in crystallization, particle technology, population balance modeling, and process synthesis. Her teaching interests include particle technology, nanotechnology, and thermodynamics.

\section{Dr. Carlen Henington, Mississippi State University}

Dr. Carlen Henington is a nationally certified school psychologist, an associate professor, and program coordinator of the Mississippi State University School Psychology programs. She completed her doctoral work at Texas A\&M University and her internship at the Munroe Meyer Institute for Genetics and Rehabilitation at the University of Nebraska Medication, Omaha. She received the Texas A\&M Educational Psychology Distinguished Dissertation Award in 1997, the Mississippi State University Phi Delta Kappa Outstanding Teaching Award in 1998, the Mississippi State University Golden Key National Honor Society Outstanding Faculty Member Award in 2000, and the Mississippi State University College of Education Diversity Award in 2011. She has served as an outside reviewer for several federally-funded educational grants and works as a consultant to the Mississippi Department of Education. She is a member of the Mississippi Governor's Interagency Coordinating Council for Early Childhood. She serves as a reviewer for program accreditation for the American Psychology Association and program approval for the National Association of School Psychologists. She has served as a grant reviewer for the U.S. Department of Education, National Science Foundation, and Safe School/Healthy Schools Imitative.

\section{Dr. Rebecca K. Toghiani, Mississippi State University}

Dr. Rebecca K. Toghiani is an associate professor of Chemical Engineering at MSU. She received her B.S., M.S. and Ph.D all in Chemical Engineering from the University of Missouri-Columbia. She received the 1996 Dow Outstanding New Faculty Award and the 2005 Outstanding Teaching Award from the ASEE Southeastern Section. A John Grisham Master Teacher at MSU, she is an inaugural member of the Bagley College of Engineering Academy of Distinguished Teachers. She has also been recognized at MSU with the 2001 Outstanding Faculty Woman Award, a 2001 Hearin Professor of Engineering award, and the 1999 College of Engineering Outstanding Engineering Educator Award. 
An Instructional Module on Thermally Coupled Columns for Undergraduate Chemical Engineering Separations 


\begin{abstract}
In the chemical processing industry companies are seeking methods for becoming more economically competitive. This includes better design of new processes as well as retrofitting existing processes. Process intensification is used by industry to reduce process costs. One method for process intensification is combining existing process units into a single unit for cost reduction due to both capital cost savings and energy savings. Although students are taught how to design single function units and how to sequence these units for a chemical manufacturing process, they are usually not taught process intensification. To help students understand these concepts, an instructional module was developed that presents thermally coupled columns and divided wall columns. This module is presented in the required undergraduate separations course.
\end{abstract}

This paper presents the module including implementation, examples and resources used. The module is designed to introduce students to the basic concepts of process intensification, and then demonstrate these concepts with thermally coupled columns such as the Petlyuk column configuration and divided wall columns. Comparisons are made between traditional distillation sequences with the thermally coupled configurations and the divided wall columns. The benefits of capital cost reduction and energy savings are emphasized. In addition to discussing the benefits of these approaches, it is emphasized that this approach will not work for all chemical systems. Since this module has been used twice with two different instructors, it is expected to be transferrable to other instructors. Assessment of student understanding is being performed using pre/post surveys on the content.

\title{
Introduction
}

Process intensification is a concept increasingly used in the chemical processing industry. Definitions of process intensification (PI) have varied over time ${ }^{1}$, but it generally refers to changes that produce a drastic improvement in a chemical manufacturing process. PI includes the concept of increasing process efficiency by combining multiple unit operations into a single equipment unit. Process efficiency can by quantified by lower operating costs, lower capital costs, energy savings, improved yield and selectivity, reduced waste, increased safety, or any combination of these items ${ }^{1,2}$. Industry is interested in process intensification because it can make companies more competitive globally.

Since distillation is the primary separation process used in the chemical processing industry and since distillation accounts for significant industrial energy usage, significant energy savings can be realized by making distillation more energy efficient. One area of process intensification is thermally coupled distillation columns including Petlyuk column arrangements and dividing wall columns. Although developed in the 1930's and 1940's ${ }^{3,4}$, basic concepts of thermally coupled columns are not typically taught in undergraduate separations courses. Although they are taught in some design courses, they are not included in the design courses at Mississippi State University. Due to the renewed interest in process intensification, a module on thermally coupled columns is being added to an undergraduate separations course. 


\section{Implementation}

The class is a junior level separations course that focuses on equilibrium staged operations, particularly distillation columns. This one semester course includes flash distillation, short-cut and rigorous calculation methods for multicomponent distillation, use of ChemCAD simulation software in column design, gas absorption and stripping, liquid-liquid extraction, and other topics as time allows. The course initially covers simple distillation columns (one feed stream, two product streams, and no side streams), rectifying columns, and stripping columns before presenting more complex columns with multiple feeds and side streams ${ }^{5}$. This new module on thermally coupled columns is introduced after the side streams are covered. Prior to module presentation, process intensification is discussed and the benefits of PI are emphasized. The module is presented in a regular 50 minute class period. Resources used to develop the module include journal articles ${ }^{1-4,6-11}$.

The approach used in class is to start with configurations of simple distillation columns (one feed stream and two product streams), and then progress to more complex column arrangements. Specifically, distillation column sequences with simple distillation columns are presented as a method for separating ternary mixtures. This is a base case scenario shows how two or three columns may be sequenced to separate three compounds, as shown in Figure 1a. In this case there is no thermal coupling between the columns, and each column has a reboiler and a condenser.

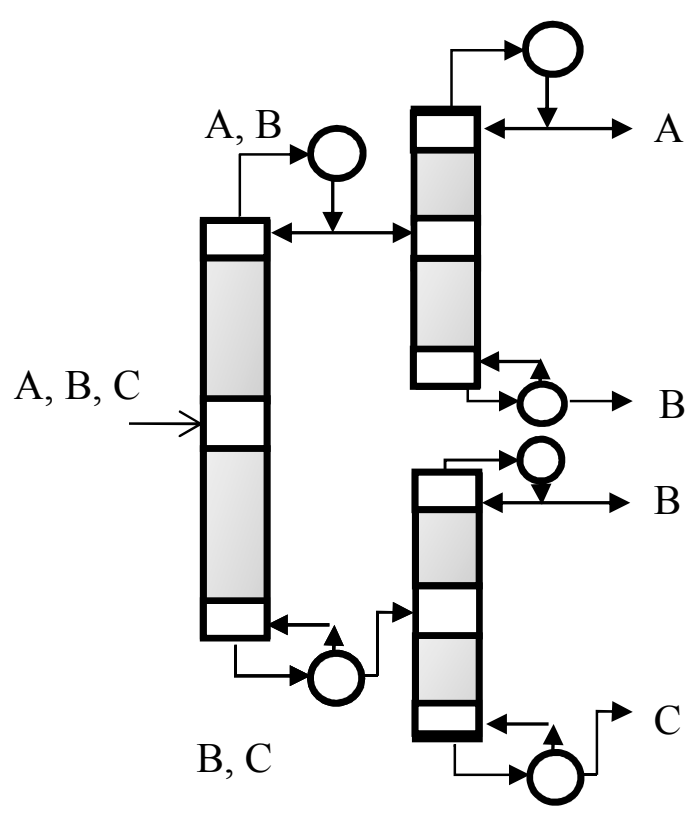

(a)

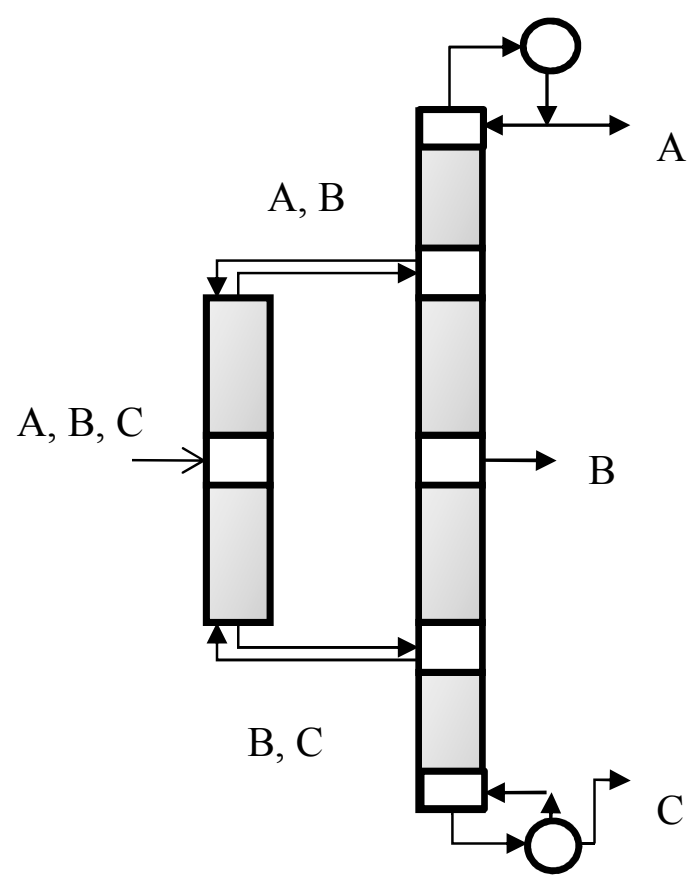

(b)

Figure 1. Two sets of distillation sequences including (a) a traditional sequence with three simple columns, and (b) a fully coupled sequence as represented by the Petlyuk column arrangement. 
The second step in the presentation is to show thermal coupling between the columns and to discuss the advantages of thermal coupling, specifically the reduction in the number of heat exchangers and the savings in energy costs. Progressive degrees of thermal coupling are shown where condensers and reboilers are removed, and streams are sent from the second column back to the first column. This development culminates in the Petlyuk column arrangement ${ }^{6,7}$ as shown in Figure 1b. The first column, often referred to as a prefractionator, doesnot have a reboiler or a condenser. Instead, the prefractionator is fed at the top and the bottom by side streams from the main (second) column. Figure 1 shows how the number of heat exchanger is reduced from six to two due to thermal coupling. In this configuration, one reboiler supplies the heat for both columns and one condenser supplies the cooling for both columns.

The module is not limited to the configurations shown in Figure 1, but it includes other configurations as presented in various journal articles ${ }^{6-9}$. One emphasis of this module is that the Petlyuk column arrangement does not work for all ternary systems and guidelines are given for determining whether this arrangement is suitable for a given ternary system. Specifically, the Petlyuk column arrangement's efficiency depends on the feed concentrations and the relative volatilities of the compounds?

Next, further thermal coupling is demonstrated with dividing wall columns. In this case the columns are combined into a single column as shown in Figure 2. The prefractionator from the Petlyuk configuration is incorporated in the dividing wall column as shown by the shaded area in Figure $2 b$. The heavy vertical line in the center of the column in Figure $2 b$ represents an adiabatic dividing wall inside the column.

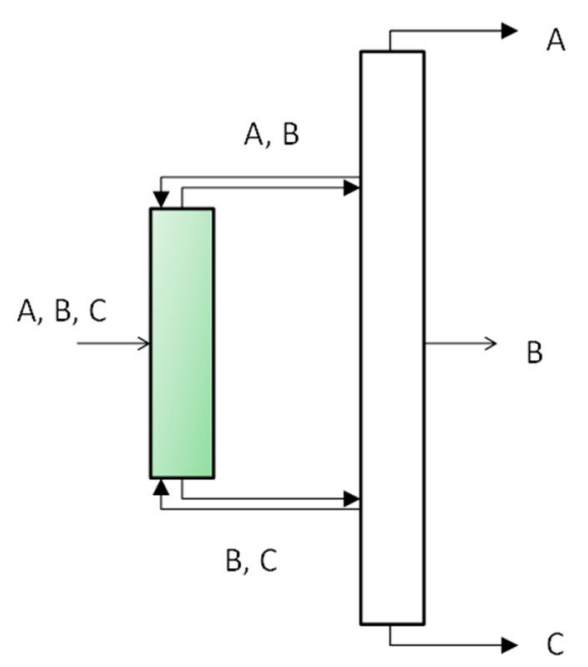

(a)

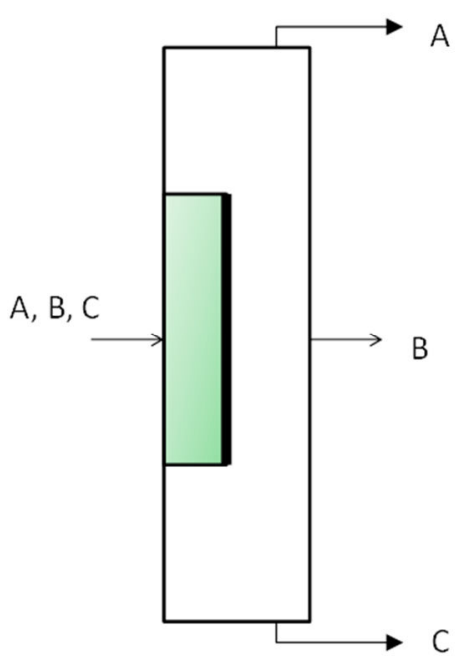

(b)

Figure 2. Two sets of distillation systems including (a) a fully coupled sequence as represented by the Petyluk column arrangement, and (b) a dividing wall column.

Throughout the presentation it is emphasized that these columns are not of academic interest only, but they are actually used in industry. Specifically, dividing wall columns are used in commercial operation by various companies including BASF and $\mathrm{UOP}^{4,10}$. An overview of patents related to thermally coupled columns is available ${ }^{4}$. Class discussion also links thermally 
coupled columns to process intensification by emphasizing that compared to a conventional multiple column sequence, energy and capital cost savings can approach $30 \%$.

Since it is essential for students to understand that dividing wall columns are not applicable to all systems, the limitations are also discussed. As in the Petlyuk column configuration, efficiency in dividing wall columns depends on the feed composition and the relative volatilities of the components $^{10}$. Other limitations include the lack of design methods, the difficulty in designing a control system for the column, and the single pressure constraint ${ }^{10}$.

\section{Assessment}

The pre/post survey used for the dividing wall columns module has the following questions.

1. In a Petlyuk arrangement of two distillation columns:

a. each column has a reboiler and a condenser

b. one column has a reboiler and a condenser, and the other column has a reboiler but no condenser

c. one column has a reboiler and a condenser, and the other column has a condenser but no reboiler

d. one column has a reboiler and a condenser, but the other column does not have a reboiler or a condenser

2. A dividing wall column is equivalent to a sequence of simple distillation columns with:
a. two column
b. three columns
c. four columns

3. The main benefits from both Petlyuk and dividing wall columns come from:
a. pressure differences
b. simplified control
c. thermal coupling

4. Advantages of dividing wall columns include which of the following (can circle more than one answer):
a. lower operating costs
b. lower capital equipment costs
c. improved process performance

These questions are designed to determine if the students comprehended the fundamental concepts of Petlyuk columns and dividing wall columns. Specifically, the questions determine if the students knew the configuration of the columns and the benefits of using the columns. The questions were scored as follows: (a) the first three questions were grouped together because they had one correct (correct or incorrect) the score for the three questions was calculated 0 (none correct) to 3 (all three questions correct); and (b) the fourth question required the students to indicate all advantages (a possible of 0 to 3 correct responses because all are an advantage). This was entered separately in the data.

This special lecture was provided to students during two different semesters (i.e., Spring 2011 and Spring 2012) by two different faculty members. For both classes, there was a significant 
difference in students' responses pre to post lecture. See Table 1 below for means for pre and post scores for both semesters and Table 2 for the results of the Paired Samples $t$ Test.

Table 1 Mean Change $(\Delta)$ Pre to Post in Students Responses Spring $2011(n=31)$ and Spring $2012(n=36)$

\begin{tabular}{|c|c|c|c|c|c|c|c|}
\hline \multirow{2}{*}{ Variable } & \multicolumn{3}{|c|}{ Spring 2011 } & \multicolumn{3}{c|}{ Spring 2012 } \\
\cline { 2 - 8 } & Pre & Post & $\Delta$ & & Pre & Post & $\Delta$ \\
\hline & & & & & & & \\
Questions 1 - 3 & $1.29(.59)$ & $2.65(.75)$ & 1.36 & & $1.33(.53)$ & $2.61(.69)$ & 1.28 \\
\hline Question 4 & $1.65(.80)$ & $2.45(.72)$ & .80 & & $1.50(.56)$ & $2.25(.73)$ & .70 \\
\hline
\end{tabular}

Note: Standard deviations provided in parentheses.

Table 2 Independent Samples Test for Pre/Post Questions

\begin{tabular}{|c|c|c|c|c|c|c|c|}
\hline \multirow{3}{*}{ Semester / Questions } & \multicolumn{4}{|c|}{ Differences } & $t$ & $d f$ & Sig. (2-tailed) \\
\hline & \multirow[b]{2}{*}{ Mean } & \multirow{2}{*}{$\begin{array}{l}\text { Std. } \\
\text { Dev. }\end{array}$} & \multicolumn{2}{|c|}{$\begin{array}{l}95 \% \text { Confidence } \\
\text { Interval of the } \\
\text { Difference }\end{array}$} & & & \\
\hline & & & Lower & Upper & & & \\
\hline $\begin{array}{l}\text { Spring } 2011 \\
\text { Questions } 1 \text { - } 3\end{array}$ & -1.35 & .91 & -1.69 & -1.02 & -8.25 & 30 & .000 \\
\hline $\begin{array}{l}\text { Spring } 2011 \\
\text { Question } 4\end{array}$ & -.81 & .79 & -1.10 & -.52 & -5.67 & 30 & .000 \\
\hline $\begin{array}{l}\text { Spring } 2012 \\
\text { Questions } 1 \text { - } 3\end{array}$ & -1.28 & .89 & -1.58 & -.98 & -8.69 & 35 & .000 \\
\hline $\begin{array}{l}\text { Spring } 2012 \\
\text { Question } 4\end{array}$ & -.75 & .87 & -1.05 & -.45 & -5.15 & 35 & .000 \\
\hline
\end{tabular}

\section{Concluding remarks}

First presented in the spring semester of 2011, it was subsequently presented by a second faculty member during the spring semester of 2012. Both lectures produced significant learning effects 
pre to post lecture. Because this was limited to a single 50-minute presentation, there was not sufficient time to cover design details. However, the goal of this module was not to have students design thermally coupled columns, but to introduce them to how process intensification can be applied with distillation columns.

Although this module was developed to present process intensification principles related to separations, the instruction may be used for other education aspects such as emphasizing lifelong learning and the connection with concepts covered in the heat transfer course. This module provides an opportunity to discuss the importance of life-long learning by discussing that although distillation is generally considered to be a mature field, there is ongoing research on dividing wall columns as evidenced by recent scholarly articles ${ }^{11}$. Since many chemical engineering students at Mississippi State University take heat transfer and separation courses concurrently, the discussion on condensers and reboilers can be used to reinforce what students are learning in heat transfer.

\section{Acknowledgment}

This material is based upon work supported by the National Science Foundation under Grant No. DUE-0837409. Portions of this paper are based on a previous presentation ${ }^{12}$.

\section{References}

[1] Van Gerven, T., and A. Stankiewicz, "Structure, energy, synergy, time - The fundamentals of process intensification," Ind. Eng. Chem. Res., 48, 2465-2474, 2009.

[2] Tsouris, C., and J. V. Porcelli, "Process intensification - Has its time finally come?," Chem. Eng. Prog., 99(10), 50-55, 2003.

[3] Olujić, Ž., B. Kaibel, H. Jansen, T. Rietfort, E. Zich, and G. Frey, "Distillation Column Internals/Configurations for Process Intensification," Chem. Biochem. Eng. Q., 17(4), 301-309, 2003.

[4] Dejanović, I., Lj. Matijašević, and Ž. Olujić, “Dividing wall column-A breakthrough towards sustainable distilling, Chemical Engineering and Processing, 49, 559-580, 2010.

[5] Wankat, P. C., Separations Process Engineering, 2nd ed., Prentice Hall: Upper Saddle River, 2007, 254-258.

[6] Petyluk, F. B., V. M. Platonov, and D. M. Slavinskii, "Thermodynamically optimal method for separating multicomponent mixtures," International Chemical Engineering, 5 (3), 555-561, 1965.

[7] Glinos, K., and M. F. Malone, "Optimality regions for complex column alternatives in distillation systems," Chem. Eng. Res. Des., 66(3), 229-240, 1988.

[8] Agrawal, R.,and Z. T. Fidkowski, "Thermodynamically efficient systems for ternary distillation," Ind. Eng. Chem. Res., 38, 2065-2074, 1999.

[9] Agrawal, R.,and Z. T. Fidkowski, “Are thermally coupled distillation columns always thermodynamically more efficient for ternary distillations?," Ind. Eng. Chem. Res., 37, 3444-3454, 1998.

[10] Schultz, M. A., D. G. Stewart, J. M. Harris, S. P. Rosenblum, M. S. Shakur, and D. E. O’Brien, "Reduce costs with dividing-wall columns." Chemical Engineering Progress, 98(5): 64-71, 2002.

[11] Ho, Y.-C., J. D. Ward, and C.-C. Yu, "Quantifying Potential Energy Savings of Divided Wall Columns Based on Degree of Remixing", Ind. Eng. Chem. Res., 50, 1473-1487, 2011.

[12] Hill, P. J., "Process Intensification Modules in a Chemical Engineering Mass Transfer Course", ASEE

Southeastern Section Annual Conference, Mississippi State, MS, April 2012. 